\title{
DETERMINING THE PREVALENCE OF TRIGGER POINTS IN ACUTE SHOULDER PAIN PATIENTS
}

\section{Albertina Nazareth ${ }^{1}$, Neeraj Athavale ${ }^{* 2}$, Drishti Kadakia ${ }^{3}$, Ashok K. Shyam ${ }^{4}$,} Parag K. Sancheti ${ }^{5}$.

${ }^{1}$ BPTh,Sancheti Institute College of Physiotherapy, Pune, Maharashtra, India.

${ }^{* 2}$ MPTh,Sancheti Institute College of Physiotherapy, Pune, Maharashtra, India.

${ }^{3}$ BPTh,Sancheti Institute College of Physiotherapy, Pune, Maharashtra, India.

${ }^{4}$ Ms.OrthoResearch Officer- Sancheti Institute for Orthopedics and Rehabilitation, Pune, Maharashtra, India.

${ }^{5}$ Ms.OrthoChairman- Sancheti Institute for Orthopedics and Rehabilitation, Pune, Maharashtra, India.

\section{ABSTRACT}

Background: Shoulder pain due to its high prevalence has great significance in its contribution to morbidity. It's the third most common musculoskeletal problem.There are two types of trigger points found they are active and latent trigger points.Active trigger points are the one which when palpated causes spontaneous pain or referred pain and latent trigger points are the one which do not cause any pain except they are present either in form of taut band or nodules. MyofascialTrigger points (MTrPs) cause a local pain syndrome. The main cause of myofascial pain syndrome are trigger points.

Purpose of the study: The purpose of the study was to determine the exact muscles that have the tendency for developing trigger points in acute shoulder pain pathologies and to see the trigger points developed are due to the shoulder pathology.

Materials and Methods: A observational study was performed. Patients were selected by convenient sampling. 70 people participated within the age of 18-65, pain duration within 3 months, males and female included with no history of recent trauma, neurovascular injuries, degenerative pathology and shoulder dislocation. Patients were assessed for myofascial trigger points (MTrPs) on both affected and non-affected side. MTrPs were assessed on different muscles by manual palpation method.

Results: The result shows that the muscle affected maximum is upper trapezius with $84.28 \%$ and pectoralis major with $71.42 \%$. Also on the affected side, upper trapezius with $37.14 \%$ and pectoralis major and subscapularis with $20.00 \%$.

Conclusion: This study showed the prevalence of trigger points in acute shoulder pain pathologies is $66.59 \%$. Each patient of any acute pathology had the presence of more than 3 trigger points in the affected side proving trigger points to be of significant importance and it is due to underlying shoulder pathology.

KEY WORDS: Acute shoulder pain, Myofascial trigger points, Myofascial pain syndrome.

Address for correspondence: NeerajAthavale, Sancheti Institute College of Physiotherapy, Shivaji Nagar, Pune -5, Maharashtra, India. E-Mail: dr.neeraj86@gmail.com

Quick Response code

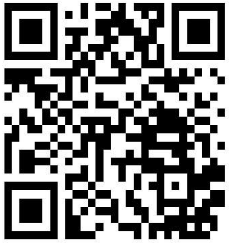

DOI: $10.16965 /$ ijpr.2019.129

\begin{tabular}{|c|c|c|}
\hline \multicolumn{3}{|c|}{ Journal Information } \\
\hline \begin{tabular}{|r} 
International Journal o \\
\begin{tabular}{|c|} 
ICV for 2016 \\
$\mathbf{8 6 . 9 3}$
\end{tabular} \\
ISSN (E) $2321-1$ \\
https://ww \\
DoI-Prefix: https
\end{tabular} & $\begin{array}{l}\text { ysiotherapy and F } \\
\text { ISSN (P) 2321-8975 } \\
\text { hr.org/ijpr.html } \\
\text { doi.org/10.16965/ijpr }\end{array}$ & $(c c)(E T-M b-5 \%$ \\
\hline \multicolumn{3}{|c|}{ Article Information } \\
\hline $\begin{array}{l}\text { Received: } 15 \text { Mar } 2019 \\
\text { Peer Review: } 15 \text { Mar } 2019 \\
\text { Revised: None }\end{array}$ & $\begin{array}{l}\text { Accepted: } 22 \text { Apr } \\
\text { Published (O): } 11 \\
\text { Published (P): } 11\end{array}$ & $\begin{array}{l}9 \\
2019 \\
2019\end{array}$ \\
\hline
\end{tabular}




\section{INTRODUCTION}

Shoulder pain due to its high prevalence has great significance in its contribution to morbidity. It's the third most common musculoskeletal problem $[1,2]$. It is estimated that the incidence of shoulder disorders ranges from 7 to 25 per 1000 consultations with general physicians.A recent survey found that the shoulder pain was most prevalent in working shoulder impingement with $13 \%$ [3]. A new episode of shoulder pain in primary care report symptom which are persistent after 6 to 12 months is seen in 40 to $50 \%$ of all patients $[4,5]$.

There are two types of trigger points found-active and latent trigger points. Active trigger points are the one which when palpated causes spontaneous pain or referred pain and latent trigger points are the one which do not cause any pain except they are present either in form of taut band or nodules [6-8]. Head, neck,shoulder and low back are the areas where most trigger points are found $[9,10]$. MTrPs cause a local pain syndrome that has significant associations with mood, health related, quality of life and function [4]. The main cause of myofascial pain syndrome are trigger points. Due to no proper definition of the myofascial pain syndromes its impact on individual life is poorly understood [11]. They are known to have motor sensory and autonomic components $[12,13]$. Trigger points causes dysfunction which is characterized by muscle shortening, muscle weakness, difficulty in relaxation, lack of coordination and fatigability and delayed recovery. Aching pain and soreness is seen in patients having trigger points which causes myofascial pain syndrome. Throbbing, burning, stabbing or sharp pain is seen in acute cases. MTrPs are considered to have a link with different types of headaches like migraine, occipital neuralgia, tension type headaches, headaches due to pericranial tenderness $[9,14]$. In clinical practice trigger points have been described as a common cause whereas its been overlooked in musculoskeletal pain $[15,16]$.

Also a recent study showed active trigger points in shoulder muscles in patients with unilateral shoulder impingement syndrome (SIS). Though this study provided new information about SIS, only the involved side and one acute shoulder pathology with a few muscles were evaluated. Assessment of the uninvolved side is equally important as it shows compensations in terms of scapular mechanics and isokinetic performance which can be noticed by the development of triggers in the overacting muscles [12]. Research done on trigger points in chronic shoulder pain patients had its limitation of not including patients in the acute phase. As it was known that MTrPs were a cause of pain in acute pain patients as well. These MTrPs in the acute phase which remained persistent if not identified and treated could have been the cause of pain and dysfunction in chronic pain syndromes [17].

There has been very few studies targeting acute shoulder pathologies. This study aims in identifying the exact muscles that have a tendency of developing trigger points in acute shoulder pathologies like rotator cuff tear, rotator cuff tendinitis, adhesive capsulitis, acromial bursitis, SIS. This would intend give a clear idea of the muscles compensating for the lost function by over recruitment and development of trigger points. This informationwould be helpful to determine the proper scapular kinetics and thus provide a more efficient and specific treatment.

\section{MATERIAL AND METHODOLOGY}

Patients: Seventy patients were recruited through convenient sampling on the basis of diagnosis by the orthopedic surgeon. Males and females within the age of $18-65$ years (Mean age- $47.8 \pm 13.36$ ) of age having shoulder pain within the duration of 3 months were the inclusion criteria.

Fibromyalgia, Recent trauma, Neurovascular injuries, Degenerative pathology, Shoulder dislocation, pregnancy, history of shoulder surgery, corticosteroid injection 3 months before evaluation, muscle relaxants or analgesics taken 72 hours before examination were excluded from the study.

Prior to the examination consent forms were given to the patients which they had to read and sign before participating in the study.

The ethical committee of the university approved this project. The patients gave their written consent and informed consent to participate in the study. 
Myofascial trigger point assessment: The MTrPs were explored in supraspinatus, infraspinatus, subscapularis, pectolaris major, upper and lower trapezius, anterior and middle deltoid, rhomboids, teres minor and lattismusdorsi by therapists who have undergone an additional course in anatomy and surface palpation and having a clinical experience of more than 6 years. A study concluded that MTrP palpation is reliable and, hence, potentially useful as a diagnostic tool in the diagnosis of myofascial pain in patients with non-traumatic shoulder pain [16]. The trigger point diagnosis was performed following the criteria described by 1) Presence of palpatory taut band in skeletal muscle 2. Presence of hyperirriGraph tender spot within the taut band 3) Local twitch response elicited by the snapping palpation of the taut band 4) Referred pain in response to MTrP compression [16].

Both the unaffected side and the affected side was assessed by the same examiner. Patients were asked to also rate their pain when palpated for MTrPSon Numerical pain scale to find the intensity of the pain [18].

Statistical Method: Data was recorded on a score sheet. The score sheet data was entered into Microsoft Excel (2013) spread sheet to be sorted and the demographic that is age was calculated.

\section{RESULTS}

Demographic and clinical data of the patients.

\section{MTrPs in conditions}

Graph 1: Prevalence of trigger points in muscles.

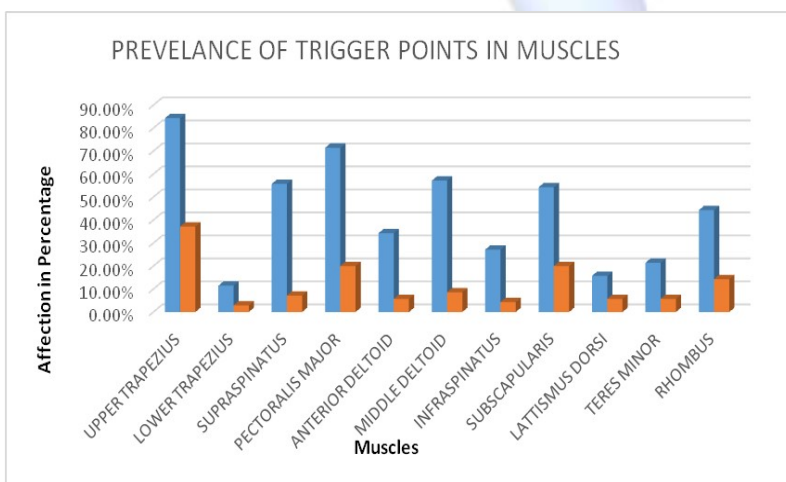

- AFFECTED IN PERCENTAGE $\square$ AFFECTED IN PERCENTAGE

Graph 1 shows the percentile calculation of prevalence of trigger points on affected and non-affectedside. The Graph shows that upper trapezius is maximally affected in both affected and non-affected side in 59 patients with $84.28 \%$ and 26 patients with $37.14 \%$ respectively. Second, pectoralis major affection in 50 patients with $71.42 \%$ followed by supraspinatus in 40 patients with $55.71 \%$ and subscapularis in 38 patients with $54.28 \%$ on affected side and pectoralis and subscapularis in 14 patients with $20.00 \%$ on non-affected side. The least common affected muscles on affected side were upper trapezius andlatissmusdorsi in 11 and 8 patients with $15.71 \%$ and $11.42 \%$ respectively and on non-affected side were infraspinatus and lower trapezius in 4 and 2 patients with $4.28 \%$ and $2.85 \%$ respectively.

\section{MTrPs in muscles affected in different conditions:}

Graph 2: Muscles affected in adhesive capsulitis on affected side

MUSCLES AFFECTED IN ADHESIVE CAPSULITIS

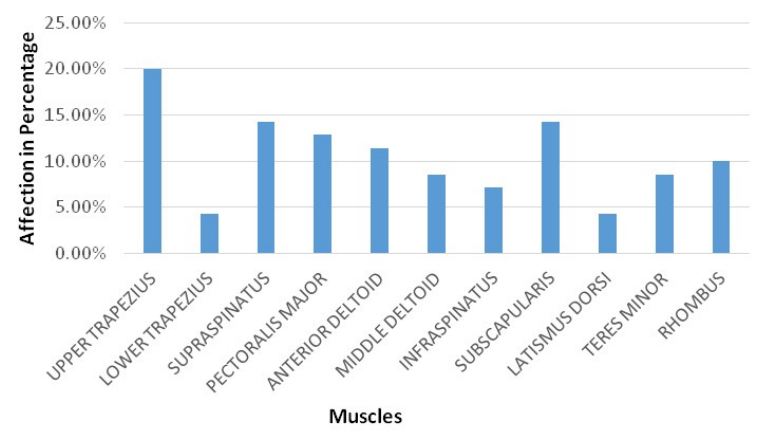

In Graph 2 shows that upper trapezius is maximally affected in 14 patients and lower trapezius and latissmusdorsi equally and least affected in 3 patients with $4.28 \%$

Graph 3: Muscles affected in Subacromial Bursitis on affected side.

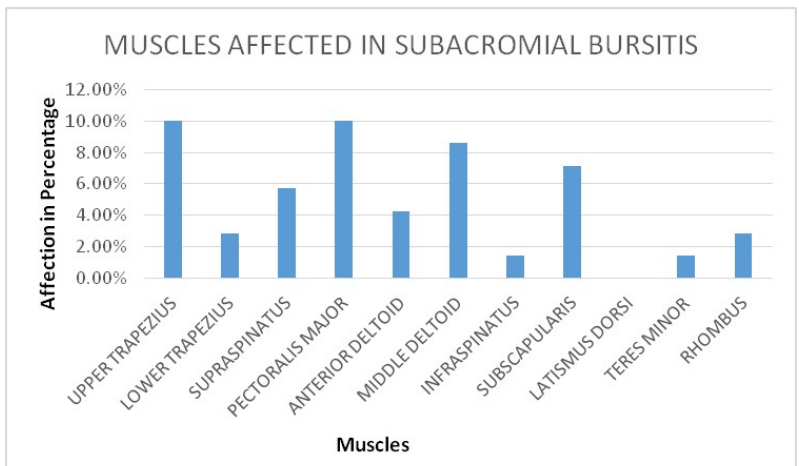

In Graph 3 , the maximally affected muscles in subacromial bursitis are upper trapezius and pectoralis major which are equally affected in 7 patients with $10.00 \%$ followed by the least affected muscles, infraspinatus and teres minor in 1 patient with $1.42 \%$. 
Graph 4: Muscles affected in rotator cuff tear on affected side.

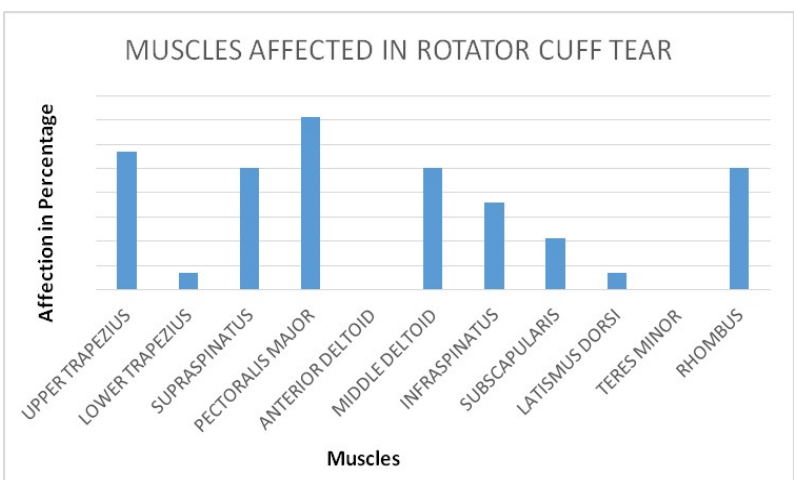

In Graph 4, pectoralis major and upper trapezius are maximally affected in 10 patients with $14.28 \%$ and the least affected were lower trapezius and latissmusdorsi in 1 with $1.42 \%$.

Graph 5: Muscles affected in bicepital tendinitis on affected side.

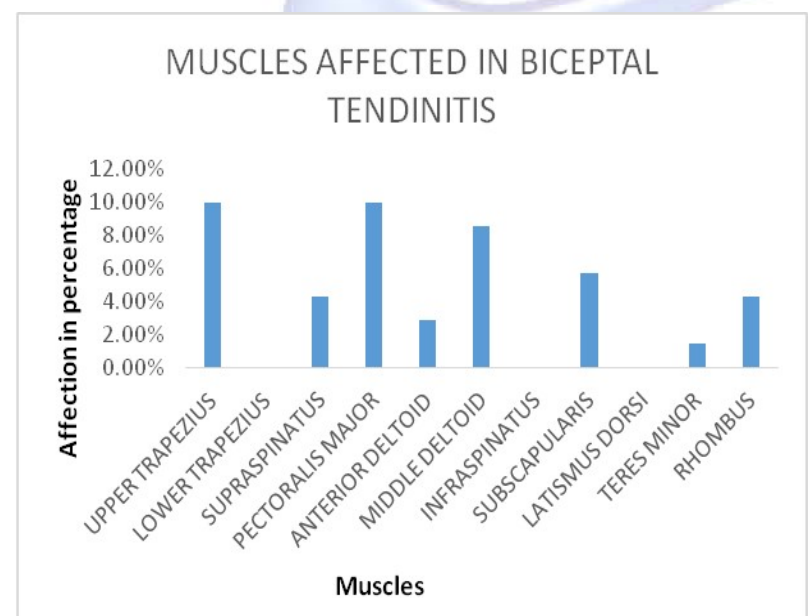

In Graph 5, upper trapezius and pectoralis major were equally affected in 7 patients with $10.00 \%$ followed by least affected teres minor in 1 patient with $1.42 \%$

Graph 6: Muscles affected in Rotator Cuff Tendinitis.

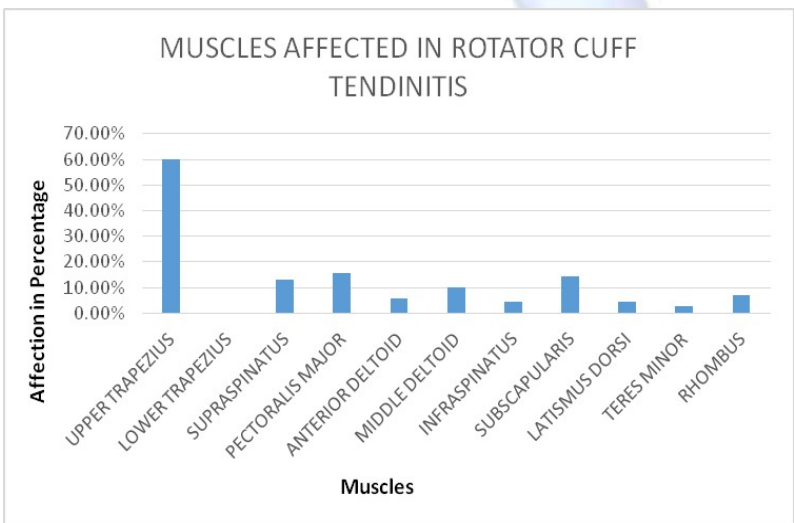

In Graph 6, the maximally affected muscle was upper trapezius in 42 patients with $60.00 \%$ and teres minor in 2 patients $2.85 \%$ with least affection.
Graph 7: Muscles affected in Impingement.

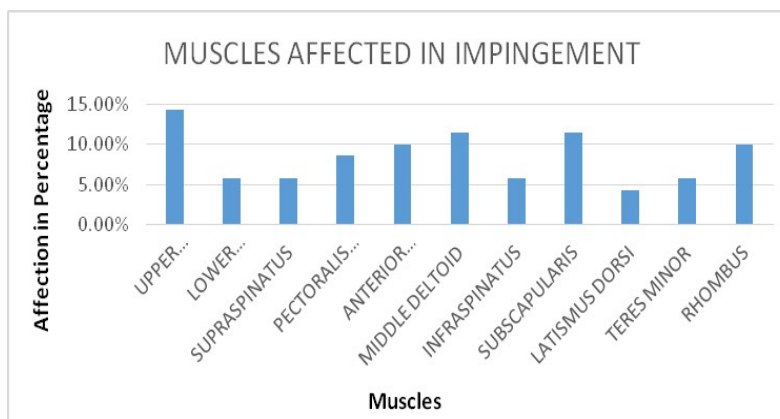

In Graph 7, upper trapezius muscle was most affected in 10 patients with $14.28 \%$. The least affected muscle waslattismusdorsi in 9 patients with $5.71 \%$.

\section{DISCUSSION}

The present study provides a different outlook to shoulder pain appearing in the acute stage. In this study it was found that amongst the non-traumatic acute shoulder pain conditions the prevalence of trigger points was found to be the most in upper trapezius, pectolaris major followed by supraspinatus and subscapularis muscles respectively, the least affected shoulder girdle muscle was lattismusdorsi and lower trapezius. This study having assessed the non-affected side showed upper trapezius and pectolaris major to be majorly affected. In another study done in chronic shoulder pain patients, upper trapezius and infraspinatus muscles were found to be largely affected.

Each patient at the very least showed the presence of 3 triggers on the affected side, thus stating that trigger points may be a considerable cause of pain and disability in the shoulder. Active MTrPs being painful spots that produce familiar shoulder pain during contraction, stretching or compressing provide an alternative explanation for shoulder pain, which is independent of the presence of subacromial abnormalities [17].

Active trigger points prevents full lengthening of the muscle and causes weakness of the muscle [19].

Active and latent trigger points are two types of trigger points seen in patients. Active trigger points are characterized by the presence of spontaneous pain whereas latent trigger points are characterized by the ones that clinically has no complain of pain but when manually palpated 
on a hypersensitive muscle area causes a referral pain elsewhere [17].

Latent trigger points can be found on asymptomatic patients on examination. Active contraction, passive stretching or prolonged and excessive use of muscles containing trigger points causing referred myofascial pain leads to the patient compensating by modifying his posture. This may be the cause of myofascial pain in asymptomatic patients.

Trigger points are mainly found in the areas of the muscles which are firm on palpation. Limited range of motion and stiffness are seen in muscles where trigger points are present [6].

As per the integrated hypothesis, one of the widely accepted theory of MTrP origin states the connection between an energy crises near the affected endplate that is affected by a noxious hi- stochemical that stimulates nociceptors. These motor end plates release excessive acetyl choline which is seen by sarcomere shortening histopathologically [20].

The most widely accepted theory supports that trigger points develop after overuse. Potential mechanisms such as eccentric overload, submaximal sustained and submaximal concentric contractions also play a role. The end result of this is lowered $\mathrm{pH}$ and subsequent increase in inflammatory mediators [6].

The formation of MTrPs is caused by persistent nociceptive input through central sensitization of the $C$ fiber nociceptive withdrawal reflex and plateau de- polarization of withdrawal agonist alpha motor neurons and compensatory reticulospinal motor facilitation of antigravity muscles and plateau depolarization of withdrawal antagonist alpha motor neurons [6].

Pain in the postural muscles have been reported to be associated with maintained low load forces and mitochondrial changes in type 1 muscle fibers pointing towards a relation amongst mechanical stress, metabolic insuffiencies and pain. This results in an altered biomechanics of the scapula and humerus and the scapula and the thorax. One muscle being over worked due to compensating for the loss of motion due to the shoulder pathology develops trigger points and causes pain leading to the antagonist muscle being overworked in future stresses [6].

This is true for latent triggers in healthy individuals, in this study the non-affected side of the patient have also shown the presence of trigger points in the postural muscles like upper trapezius and pectolaris major. Owing to altered posture in the affected side of the shoulder, the non-affected side also develops some postural changes with respect to different loads on the shoulder. This again results in few muscles over compensating for the weak stabilizing muscles.

A study stated that the presence of trigger points initially which are less in number which due to its presence there is modification in the pattern of muscle recruitment.

A study done in chronic shoulder pain patients suggested that there is high prevalence of trigger points in shoulder girdle muscles which have resulted in altered biomechanics. These triggers if diagnosed and released in their acute stage and then trained for proper scapular motor control would lead to a better recovery [17].

Therefore careful analysis of the history of pain and a consistent physical examination helps in diagnosis of myofascial pain which in turn benefit to reduce the time duration in healing phase of shoulder pathologies thus improving the quality of life.

Limitations: Owing to the less time period, the study could not implement an intervention.

Future scope of study: Post releasing of these trigger and proper scapular training follow up after 1 or 2 years to review the patient developed into its chronic condition. Due to no proper distribution of patients in each condition we could not justify in which condition maximum affection was seen. This can be the future scope.

\section{CONCLUSION}

This study showed the prevalence of trigger points in acute shoulder pain pathologies is $66.59 \%$. Each patient of any acute pathology had the presence of more than 3 trigger points in the affected side proving trigger points to be of significant importance and it is due to underlying shoulder pathology.

\section{ABBREVIATIONS}

MTrPs- Myofascialtrigger points

SIS- Shoulder impingement syndrome 


\section{ACKNOWLEDGEMENTS}

I take this opportunity to thank Dr. NileshKamat for recruiting the patients. I would also like to thank Dr. DharaKapoor (PT) and Dr. Rachna Dabadghav (PT), Dr. NilimaBedekar and DrVivekKulkarnifor their support and guidance. I would like to thank our management and ethical committee for permitting me to undertake this study. Lastly, I extend my warm gratitude to all the people who have participated in this research.

\section{Conflicts of interest: None}

\section{REFERENCES}

[1]. Perez-Palomares S, Oliván-Blázquez B, Arnal-Burró AM, Mayoral-Del Moral O, Gaspar-Calvo E, de-laTorre-Beldarraín ML, López-Lapeña E, Pérez-Benito $\mathrm{M}$, Ara-Loriente V, Romo-Calvo L. Contributions of myofascial pain in diagnosis and treatment of shoulder pain. A randomized control trial.BMC musculoskeletal disorders. 2009 Dec;10(1):92.

[2]. Mitchell C, Adebajo A, Hay E, Carr A. Shoulder pain: diagnosis and management in primary care. BMJ: British Medical Journal. 2005 Nov 12;331(7525):1124.

[3]. Hidalgo-Lozano A, Fernández-de-las-Peñas C, AlonsoBlanco C, Ge HY, Arendt-Nielsen L, Arroyo-Morales M. Muscle trigger points and pressure pain hyperalgesia in the shoulder muscles in patients with unilateral shoulder impingement: a blinded, controlled study. Experimental brain research. 2010 May 1;202(4):915-25.

[4]. Kuijpers T, van Tulder MW, van der Heijden GJ, Bouter LM, van der Windt DA. Costs of shoulder pain in primary care consulters: a prospective cohort study in The Netherlands. BMC Musculoskeletal Disorders. 2006 Dec;7(1):83.

[5]. Croft P, Pope D, Silman A. The clinical course of shoulder pain: prospective cohort study in primary care. Primary Care Rheumatology Society Shoulder Study Group. BMJ: British Medical Journal. 1996 Sep 7;313(7057):601.

[6]. Bron C, Dommerholt JD. Etiology of myofascial trigger points. Current pain and headache reports. 2012 Oct 1;16(5):439-44.

[7]. Simons DG, Travell JG, Simons LS. Myofascial pain and dysfunction: the trigger point manual, Vol 1, upper half of body. London, Lippincott Williams and Wilkins. 1999.

[8]. Fricton JR, Kroening R, Haley D, Siegert R. Myofascial pain syndrome of the head and neck: a review of clinical characteristics of 164 patients. Oral surgery, oral medicine, oral pathology. $1985 \mathrm{Dec}$ 1;60(6):615-23.

[9]. Davidoff RA. Trigger points and myofascial pain: toward understanding how they affect headaches. Cephalalgia. 1998 Sep;18(7):436-48.
[10]. Fricton JR. Myofascial pain syndrome: characteristics and epidemiology. Advances in pain research and therapy. 1990;17:107-27.

[11]. Gerber LH, Sikdar S, Armstrong K, Diao G, Heimur J, Kopecky J, Turo D, Otto P, Gebreab T, Shah J. A systematic comparison between subjects with no pain and pain associated with active myofascial trigger points. PM\&R. 2013 Nov;5(11):931-8.

[12]. Alburquerque-Sendín F, Camargo PR, Vieira A, Salvini TF. Bilateral myofascial trigger points and pressure pain thresholds in the shoulder muscles in patients with unilateral shoulder impingement syndrome: a blinded, controlled study. The Clinical journal of pain. 2013 Jun 1;29(6):478-86.

[13]. Dommerholt J, Bron C, Franssen J. Myofascial trigger points: an evidence-informed review. Journal of Manual \& Manipulative Therapy. 2006 Oct 1;14(4):203-21.

[14]. Olesen J, Langemark M. Mechanisms of tension headache. A speculative hypothesis.Basic mechanisms of headache. Elsevier, Amsterdam. 1988:457-61.

[15]. Celik D, Yeldan Ý. The relationship between latent trigger point and muscle strength in healthy subjects: a double-blind study. Journal of back and musculoskeletal rehabilitation. 2011 Jan 1;24(4):251-6.

[16]. Gerwin RD, Shannon S, Hong CZ, Hubbard D, Gevirtz R. Interrater reliability in myofascialtrigger point examination. Pain. 1997 Jan 1;69(1-2):65-73.

[17]. Bron C, De Gast A, Dommerholt J, Stegenga B, Wensing $M$, Oostendorp RA. Treatment of myofascial trigger points in patients with chronic shoulder pain: a randomized, controlled trial. BMC medicine. 2011 Dec;9(1):8.

[18]. Bijur PE, Latimer CT, Gallagher EJ. Validation of a verbally administered numerical rating scale of acute pain for use in the emergency department. Academic Emergency Medicine. 2003 Apr 1;10(4):390-2.

[19]. Bron C, Dommerholt J, Stegenga B, Wensing M, Oostendorp RA. High prevalence of shoulder girdle muscles with myofascial trigger points in patients with shoulder pain. BMC musculoskeletal disorders. 2011 Dec;12(1):139.

[20]. Sacramento LS, Camargo PR, Siqueira-Júnior AL, Ferreira JP, Salvini TF, Alburquerque-Sendín F. Presence of Latent Myofascial Trigger Points and Determination of Pressure Pain Thresholds of the Shoulder Girdle in Healthy Children and Young Adults: A Cross-sectional Study. Journal of manipulative and physiological therapeutics. 2017 Jan 1;40(1):31-40.

How to cite this article: Albertina Nazareth, Neeraj Athavale, Drishti Kadakia, Ashok K. Shyam, Parag K. Sancheti. DETERMINING THE PREVALENCE OF TRIGGER POINTS IN ACUTE SHOULDER PAIN PATIENTS. Int J Physiother Res 2019;7(3):3098-3103. DOI: 10.16965/ ijpr.2019.129 